large amounts of tryptamine'. The word 'tryptophan' was used in error.

Institute of Neurology,

$$
\text { G. Curzon. }
$$

London, W.C.I.

\section{CONCURRENCE OF TURNER'S} SYNDROME AND ANOREXIA NERVOSA

\section{DeAr SiR,}

We were interested to read the paper by Forssman, Mellbin and Wahinder published in the Journal (February 1970, pp. 221-5). We should like to describe another case of the concurrence of these two syndromes, which is of particular interest in that the patient was one of a dizygotic twin pair, the co-twin being 'normal' physically, but being important in the psychopathology of the twin with Turner's Syndrome. This case was one of a series of 17 patients ( 16 female and 1 male) described in a paper on Anorexia Nervosa presented at the Annual Meeting of the Australian and New Zealand College of Psychiatrists in October, 1969.

She was referred to an endocrine out-patient clinic at the age of 14 for investigation of her small size and her amenorrhoea. Physical examination suggested Turner's Syndrome to the endocrinologist, and this was confirmed on chromosomal analysis. She was, at this stage, $133 \mathrm{~cm}$. ( $4 \mathrm{ft} .5 \mathrm{in}$.) and weight $35 \mathrm{~kg}$., compared to her sister's height of $158 \mathrm{~cm}$. ( $5 \mathrm{ft} .3$ in.) and weight $50 \mathrm{~kg}$. The latter had started menstruating at the age of I 1 years.

The twin with Turner's Syndrome was subsequently referred to a psychiatrist because of progressive loss of weight and increasing distress at her slight size and appearance in comparison with her twin sister. Her weight by this time had dropped to $22 \mathrm{~kg}$. (48 lb.)

Psychiatric examination showed a marked reactive depressive condition. This appeared to be largely the result of repeatod comparisons made by friends and relatives about the difference in the physical, intellectual and emotional development of the twins; these always being unfavourable to the smaller one. She also showed a marked disturbance in her attitude to food. She had started dieting some months previously following her sister's attempts to reduce weight. The latter, however, had stopped the diet, but the patient had continued. She took very little food, and no fats or carbohydrates. Her parents had tried various techniques to persuade her to eat, including pleading, threats and ignoring her, all without effect. They stated she regarded food 'like poison' and if forced to eat became 'hysterical' or hid the food in her pockets. Like the case described by Forssman et al., this patient's parental relationships appeared to have been congenial and relaxed until the development of her anorexia. Interview with the parents showed the mother to be a somewhat anxious person and concerned about her daughter's health, but the father was a warm and relaxed individual.

She was admitted to a psychiatric unit, and put on anti-depressants, phenothiazines and modified insulin. Over a period of two months she regained her previous weight of $35 \mathrm{~kg}$.

She has been followed up 15 months since then, and has required one further admission for an anorexic period when her weight fell to $25 \mathrm{~kg}$. She has also had treatment with oestrogens, which have promoted some breast development and withdrawal bleeds: however, these do not appear to have helped her much psychologically as yet. EEG showed that there was a mild general excess of theta activity and anteriorly fast rhythms were prominent. During overbreathing a few bursts of theta activity with phase reversals were seen in the right posterior temporal region, the record otherwise remaining relatively stable. The record was mildly abnormal, due to the presence of some slow episodes, focal in the right posterior temporal area, during overbreathing. No other abnormality was present.

Anorexia Nervosa and Turner's Syndrome are both relatively rare conditions. Although the Anorexia Nervosa in this patient appeared to be precipitated by her depression at her unfavourable comparison with her twin sister, the association of two rare conditions, the EEG abnormalities, and the relative absence of parental psychopathology, suggests an underlying genetic predisposition.

John A. Dickens.

University of Adelaide Department of Mental Health, Queen Elizabeth Hospital,

Woodville, Soulh Australia.

\section{PHENELZINE IN OBSESSIONAL NEUROSIS}

\section{DeAr Sir,}

We should like to report a case of obsessional neurosis which has been treated with phenelzine. The present case shows many similarities to that reported by Annesley (1969), the main difference between the two patients being the age of presentation.

At the present time our patient, a male, is aged 26 years, and his last admission to hospital had a duration of almost two years. He has had four admissions, all fairly lengthy, to the same hospital in the past four years, and had also had five admissions to two other psychiatric hospitals in Liverpool. 
He was apparently well until twelve years ago when his father died suddenly at the age of 57 from coronary thrombosis. Immediately following his father's death, the patient began ruminating about death, and after leaving school at 15 he remained in the home for two years. During this period his mother reported that he refused to wash at all.

Over the next few years he was obsessed with the following list of ideas:

(i) Fear of becoming homosexual, having on one occasion tried to insert his penis into his own rectum.

(ii) Fear of developing breasts and becoming hairy.

(iii) Fear of shaving in case he bled to death.

(iv) Fear of taking an overdose or of drinking poison.

(v) Fear of dying in his sleep, which led him to pace the floor at night disturbing his family.

(vi) Fear of violence.

(vii) The number of words in a sentence became a matter of prolonged rumination.

His last admission, in 1968, was precipitated by the patient developing uncontrollable ideas that there was a piece of paper in his rectum upon which was written 'something to do with homosexuality'. During this last phase he demanded constant reassurance from everybody with whom he came into contact and caused a great deal of antagonism amongst the other patients.

Physical examination, including chest and skull $X$-rays and EEG, revealed no abnormality.

Psychometry showed him to be of low-average intelligence, 25th percentile on Mill Hill Vocabulary Test and Progressive Matrices. There was no evidence, on psychometric testing, of schizophrenic thought disorder.

Previous treatment had included prolonged courses of ECT, phenothiazines, tranquillizers, tricyclic anti-depressants and relaxation therapy, and in December 1967 he had a pre-frontal leucotomy which provided only temporary relief.

On review in January 1970 it was noted that he had never received a monoamine oxidase inhibitor.

Phenelzine was started in doses of $15 \mathrm{mgm}$. t.d.s., and within two weeks there has been a complete change in his behaviour. He looked relaxed, did not complain, talked freely and was able to go to the town, which he had not been able to do for over twelve months.

Improvement has been maintained for four months; the patient is now back at home symptomfree.

In view of this it seems that mono-amine oxidase inhibitors may have a place in the treatment of obsessional neurosis and are worthy of trial in this intractable incapacitating illness.
We wish to thank Professor Alistair Munro for his help and advice and for permission to publish this case.

V. K. JaIn.

R. P. SWINSON.

J. G. Thоmas.

University of Liverpool Department of Psychiatry,

6 Abercromby Square,

P.O. Box 147 ,

Liverpool $L 69{ }_{3} B X$.

\section{REFERENCE}

AnNesley, P. T. (1969). 'Nardil respanse in a chronic obsessive compulsive.' British Fournal of Psychiatry, 115,748 .

\section{BURDEN RESEARCH MEDAL AND PRIZE}

\section{DEAR SIR,}

You kindly included an announcement of the above in the British Journal of Psychiatry in your November 1969 issue. The first Burden Research Medal and Prize for outstanding research work in the field of mental subnormality, published or presented as a paper to a learned Society during 1969 , has been awarded to Dr. Barry Richards, St. Lawrence's Hospital, Caterham, Surrey. The presentation was made on Monday, 8 June, at a luncheon of the Burden Trustees, held at Stoke Park Hospital, Bristol.

Stoke Park Hospital,

W. A. Heaton-Ward.

Stapleton,

Bristol BSI6IQU.

\section{GRADUAL WITHDRAWAL OF TRANQUILLIZERS WITH THE HELP OF ASCORBIC ACID}

Dear Sir,

Since the introduction of tranquillizing drugs in the treatment of mental illness and behaviour disorders in mentally retarded patients, many good and many adverse effects of the drugs have been reported. Numerous papers have appeared dealing with the question of the most suitable drugs, the length of treatment, dosages, combination of treatments and effects of sudden or intermittent withdrawal of the drugs (Whittaker and Hoy, 1963; Prien et al., 1969; Abenson, 1969).

We are reporting the results of the first two years of a tranquillizer-withdrawal scheme, which consisted of three months of gradual withdrawal of tranquillizers and their replacement-tablet for 